\title{
Occurrence characteristics of electromagnetic ion cyclotron waves at sub-auroral Antarctic station Maitri during solar cycle 24
}

\author{
Aditi Upadhyay ${ }^{1 *}$, Bharati Kakad ${ }^{1}$, Amar Kakad $^{1}$, Yoshiharu Omura ${ }^{2}$ and Ashwini Kumar Sinha ${ }^{1}$
}

\begin{abstract}
We present a statistical study of electromagnetic ion cyclotron (EMIC) waves observed at Antarctic station (geographic $70.7^{\circ} \mathrm{S}, 11.8^{\circ} \mathrm{E}, \mathrm{L}=5$ ) on quiet and disturbed days during 2011-2017. The data span a fairly good period of both ascending and descending phases of the solar cycle 24, which has witnessed extremely low activity. We noted EMIC wave occurrence by examining wave power in different frequency ranges in the spectrogram. EMIC wave occurrence during ascending and descending phases of solar cycle 24, its local time, seasonal dependence and durations have been examined. There are total 2367 days for which data are available. Overall, EMIC waves are observed for $3166.5 \mathrm{~h}(\approx 5.57 \%$ of total duration) which has contributions from 1263 days. We find a significantly higher EMIC wave occurrence during the descending phase $(\approx 6.83 \%)$ as compared to the ascending phase $(\approx 4.08 \%)$ of the solar cycle, which implies nearly a twofold increase in EMIC wave occurrence. This feature is attributed to the higher solar wind dynamic pressure during descending phase of solar activity. There is no evident difference in the percentage occurrence of EMIC waves on magnetically disturbed and quiet days. On ground, EMIC waves show marginally higher occurrence during winter as compared to summer. This seasonal tendency is attributed to lower electron densities and conductivities in the ionosphere, which can affect the propagation of EMIC waves through ionospheric ducts. In local time, the probability distribution function of EMIC wave occurrence shows enhancement during 11.7-20.7 LT (i.e., afternoon-dusk sector). Daily durations of EMIC waves are in the range of 5-1015 min and it is noted that the longer duration (240-1015 min) events are prevalent on quiet days and are mostly seen during the descending phase of solar cycle.
\end{abstract}

Keywords: ULF wave, EMIC occurrence, Solar cycle, Induction coil magnetometer

\section{Introduction}

The electromagnetic ion cyclotron (EMIC) waves are generated by the cyclotron-resonant instability of anisotropic medium-energy ring current ions (10-100 keV) (Cornwall 1965; Kennel and Petschek 1966). The ions responsible for the wave generation can be proton $\mathrm{H}^{+}$, helium $\mathrm{He}^{+}$, and oxygen $\mathrm{O}^{+}$and they determine the

\footnotetext{
*Correspondence: aditiu147@gmail.com

${ }^{1}$ Indian Institute of Geomagnetism, New Panvel, Navi Mumbai, India Full list of author information is available at the end of the article
}

stop band frequency for the EMIC waves. These waves are transverse plasma waves, and can be observed in the Earth's magnetosphere by various satellites, like AMPTE/ CCE (Anderson et al. 1990), Viking (Erlandson et al. 1990), Cluster (Pickett et al. 2010), THEMIS (Usanova et al. 2012), Polar (Carson et al. 2013), GOES (Park et al. 2016), Arase (Shoji et al. 2018), and Van Allen Probe (Fu et al. 2018). The Cluster and THEMIS observations have reported the EMIC-triggered coherent emissions having rising tone frequencies (Pickett et al. 2010; Nakamura et al. 2015). These rising tone emissions consist of 
subpacket structures (Shoji and Omura 2013; Nakamura et al. 2015), whose dynamics is governed by the nonlinear wave growth. The EMIC waves can undergo anomalous cyclotron resonance with relativistic electrons (Lorentzen et al. 2000; Summers and Thorne 2003) and are known to play a substantial role in the loss mechanism of $\mathrm{MeV}$ electrons in the radiation belt (Bortnik et al. 2006; Usanova et al. 2014; Shprits et al. 2017). They also interact with ring current ions and cause them to precipitate into the mid-latitude ionosphere, resulting in the isolated proton auroras (Nomura et al. 2012; Søraas et al. 2013; Ozaki et al. 2018). A statistical study of EMIC waves conducted by Meredith et al. (2003) suggests that the energy range for electrons that can resonate with the wave spans a wide range and may go up to $50 \mathrm{MeV}$. Generally, $\mathrm{MeV}$ electrons can penetrate deeper in the Earth's atmosphere and affect the neutral dynamics at lower altitudes (Tsurutani et al. 2016). Therefore, studies of the EMIC waves are important for better understanding of their overall role in the particle dynamics in the Earth's magnetosphere-ionosphere-atmosphere coupled system.

The EMIC waves generated in the equatorial magnetospheric region (Pickett et al. 2010; Omura et al. 2010), propagate towards the mid-latitude ionosphere, following geomagnetic field lines. When these waves reach the ionosphere, horizontal structuring in the F-region acts as a duct. Some of EMIC wave packets can be trapped into such ionospheric duct, which causes the EMIC wave to propagate horizontally to lower or higher latitudes. This way, the wave information can propagate thousands of kilometers (Johnson and Cheng 1999; Kim et al. 2011). Some of EMIC wave energy can leak to the atmosphere from the duct wall while propagating, and their signatures can be manifested as geomagnetic pulsations in the Pc1-Pc2 frequency range $(0.1-5 \mathrm{~Hz})$. The EMIC wave propagation to the ground can be much complex because its characteristics such as polarization, wave power and wave normal angle change during their propagation (Allen et al. 2015; Kim and Johnson 2016). Satellite observations, e.g., CRESS (Loto'aniu et al. 2005) and GOES (Clausen et al. 2011), showed that these waves are left-handed polarized in the generation region. Using magnetic field data from an array of five ground-based magnetometers situated between $\left(62^{\circ}\right.$ and $\left.87^{\circ} \mathrm{S}\right)$, Kim et al. (2010) suggested that after the entry of EMIC waves in the ionospheric duct, they tend to move poleward and their sense of polarization changes from left hand to right hand. A study by Kakad et al. (2018) reported that EMIC waves observed at Maitri are mainly associated with right-handed elliptical polarization. Mann et al. (2014) have observed EMIC waves from the ground array of magnetometers in Canada and found that the polarization of EMIC waves depends upon the relative location of wave injection region and the location of magnetometer. A recent study using ground observation has demonstrated that the amplitude-frequency dependence of the EMIC wave subpacket structures proposed by theoretical studies (Omura et al. 2010; Shoji and Omura 2013) remain unaltered during their propagation to the ground (Kakad et al. 2018). Thus, the ground observations of EMIC waves can be useful to get some information about their source region in the magnetosphere.

Mursula et al. (1991) studied the long-term behavior of Pc1 pulsations and reported that annual EMIC wave occurrence varies with solar cycle. Later, Mursula et al. (1996) have studied the occurrence of Pc1 waves using simultaneous satellite (AMPTE/CCE) and ground observations for two periods of contrasting solar activity levels (i.e., low and high). They found that the total occurrence rate of Pc1 waves in space decreased by a factor 1.6 from low to high sunspot times, and it is in good agreement with a simultaneous decrease in occurrence observed on the ground. Kangas et al. (1998) have provided a review of the occurrence of Pc1 waves and its link with the geomagnetic storm, solar cycle, Sun's and Earth's rotation and orbital motion. A recent study carried out using EMIC observations at Halley station in Antarctica, indicates that the frequency of EMIC wave is also influenced by the solar activity (Lessard et al. 2015). There is observational evidence that supports the solar activity influence on the EMIC wave occurrence. However, the mechanism responsible for such dependence is not well understood. The solar activity influence on EMIC waves might be linked through the variations in interplanetary solar wind parameters like density, velocity, and dynamic pressure. A study by Guglielmi et al. (2005) indicates that the occurrence of Pc1 waves at Sodankyla, Finland $(L=5.1)$ is controlled by the higher solar wind density and low values of solar wind velocity. Also, the role of solar wind dynamic pressure in exciting EMIC waves has been established through satellite observations (Usanova et al. 2012). In this context, to get a better scenario, comprehensive statistical studies of EMIC waves from the ground as well as satellite observations are needed.

In this paper, we present a statistical study of occurrence and characteristics of EMIC waves using the 7 years (2011-2017) of ground-based observations from sub-auroral station Maitri. The observation period covers 40 months in the ascending phase and 44 months in the descending phase of the solar cycle 24 . The study of current solar cycle would be interesting because of extremely low solar activity during its progression. Such a decrease in the peak solar activity as compared to the preceding solar cycle 23 has not been experienced for earlier solar cycles (SCs) (Kakad et al. 2019b). Also, solar wind dynamic pressure is considerably lowered during SC 24 . 
In such scenario, it is worth exploring the EMIC wave activity and its linkage to different solar wind parameters. Here, we extracted the information about EMIC wave occurrence during quiet and disturbed days and then examined its solar activity, seasonal, and local time dependence. We have also examined the variation of the accompanying interplanetary solar wind parameters to understand their role in the occurrence of EMIC waves.

The present paper is structured as follows. The information about the experimental setup and identification of the occurrence of EMIC waves are detailed in "Data analysis and EMIC wave identification" section. Overall occurrence of EMIC waves is discussed for ascending and descending phase in "EMIC wave occurrence and solar cycle dependence" section. The seasonal and local time dependence of EMIC waves is discussed in "Seasonal and local time dependence" section. The daily duration of the EMIC waves is presented in "EMIC wave durations" section. The variation of interplanetary solar wind parameters and ionospheric conditions during 2011-2017, and their relation to the EMIC wave occurrence are discussed in 'Discussion' section. The present work is summarized and concluded in "Summary" section.

\section{Data analysis and EMIC wave identification}

We have used the induction coil magnetometer (ICM) data from the Indian Antarctic station Maitri (geographic co-ordinates: $70.7^{\circ} \mathrm{S}, 11.8^{\circ} \mathrm{E}$; geomagnetic co-ordinates: $63.1^{\circ} S, 53.6^{\circ} \mathrm{E}$ ) which corresponds to the magnetic shell $L \sim 5$. In addition, we have used ionospheric conductivities obtained from the model provided by WDC Kyoto (see http://wdc.kugi.kyoto-u.ac.jp/) and electron density from International Reference Ionosphere (IRI) model (see http://irimodel.org/). The interplanetary solar wind parameters of one hour resolution at the Earth's bow-shock nose are obtained from OMNIWeb. We used F10.7 cm solar flux data from http://www.spaceweath er.gc.ca/. The LEMI-30 model of ICM procured from Lviv Centre of Institute for Space Research, Ukraine, consists of three induction coil magnetic sensors with communication and data acquisition system. It has been operational at Maitri since 2011. The ICM measures the variations in the magnetic field $(d B / d t)$ in north-south $(+x$ is north), east-west ( $+y$ is east) and vertical direction $(+z$ is downward) directions. The sampling rate of ICM data is $64 \mathrm{~Hz}$ during January 2011-November 2015 and $256 \mathrm{~Hz}$ from December 2015 onwards. The magnetic field variations recorded by three coils at time $t$ are taken as $B_{\mathrm{x}}(t), B_{\mathrm{y}}(t)$, and $B_{\mathrm{z}}(t)$. We computed the Fourier spectrogram for each component by taking a window of $90 \mathrm{sec}$ with an overlap of $80 \%$. Thus, the spectrogram has a resolution of $0.011 \mathrm{~Hz}$ and $18 \mathrm{sec}$ in frequency and time domain, respectively. Let $P_{\mathrm{x}}^{f}(t), P_{\mathrm{y}}^{f}(t)$, and $P_{\mathrm{Z}}^{f}(t)$ be the power spectral densities of these three magnetic field components. The Fourier spectrogram of total magnetic field variation is obtained using: $B(f, t)=P_{\mathrm{x}}^{f}(t)+P_{\mathrm{y}}^{f}(t)+P_{\mathrm{z}}^{f}(t)$, where $B(f, t)$ represents the power in Fourier spectrogram at time $t$ and frequency $f$ in units of $\mathrm{nT}^{2} / \mathrm{Hz}$.

The first step in the present study is to identify the occurrence of EMIC waves. This is accomplished by examining the Fourier spectrograms of total magnetic field variations recorded by ICM for each day. In general, the EMIC waves are in the frequency range of 0.1-5 $\mathrm{Hz}$. Through visual inspection of EMIC wave spectrogram, it is found that the occurrence of EMIC waves were below $2 \mathrm{~Hz}$ at Maitri station. So we divided the frequency range into 4 parts, which enables us to get information of EMIC waves through smooth scanning of spectrograms. The chosen frequency ranges are: (i) $f_{1}=0.12-0.5 \mathrm{~Hz}$, (ii) $f_{2}=0.5-1 \mathrm{~Hz}$, (iii) $f_{3}=1-1.5$ $\mathrm{Hz}$ and (iv) $f_{4}=1.5-2 \mathrm{~Hz}$. For a given time $t$, we averaged the power of the Fourier spectrogram from lower to upper limiting frequency of each frequency bin. For example, for the first frequency bin $f_{1}$, we have averaged $B(f, t)$ from 0.12 to $0.5 \mathrm{~Hz}$ and got the variation of $\langle B(f, t)\rangle$ as a function of time, and then it was repeated for other frequency bins, namely $f_{2}, f_{3}$ and $f_{4}$. For a given frequency bin, when averaged power of Fourier spectrogram is above $-100 \mathrm{nT}^{2} / \mathrm{Hz}$, those time intervals are treated as the periods of EMIC wave activity. The limit of $-100 \mathrm{nT}^{2} / \mathrm{Hz}$ is used because the averaged power of Fourier spectrogram in the absence of EMIC wave activity lies below this threshold power. By applying this limit we assure the selection of genuine and sufficiently strong (much above the noise level) EMIC wave events. Here, we do not associate the chosen frequencies with EMIC wave bands (for example proton or helium bands). It is because the identification of EMIC wave bands in the satellite observations is relatively easy, as one has the information about the local in situ ambient magnetic field, ion composition and density. As the local gyro-frequency of the given species $\left(\mathrm{H}^{+}\right.$or $\mathrm{He}^{+}$or $\left.\mathrm{O}^{+}\right)$is available, one can associate observed EMIC waves with these bands. However, identifying frequency bands from the ground observations of EMIC waves is not straightforward. While it propagates through the ionospheric duct (Johnson and Cheng 1999; Kim and Johnson 2016), the wave gets damped and undergoes polarization shift, which makes it difficult to predict its source region and generation conditions. Also, when wave travels along magnetic field line and come to its footprint in the ionosphere, it can travel to high- or mid-latitudes through ducted propagation from that point and may get detected by the ground magnetometers. In such scenario, we do not know the L-shell of the generation region. The propagation of EMIC wave 
to ground through ionospheric duct is complex and one needs modeling efforts to understand it better.

For a better visualization of selection of an event, we provide two different examples of the EMIC wave events in Figs. 1 and 2, which occurred on 13 May 2011 and 6 September 2017, respectively. In each figure, the upper panel depicts the corresponding Fourier spectrogram of variation in total magnetic field recorded by ICM, whereas the lower panel shows the variation of averaged power of the Fourier spectrogram (i.e., $\langle B(f, t)\rangle)$ for different frequency bins namely: $f_{1}$ (black), $f_{2}$ (red), $f_{3}$ (blue), and $f_{4}$ (green). For 13 May 2011 (see Fig. 1) the occurrence of EMIC wave is observed in $f_{1}$ frequency only, and the time of occurrence of EMIC activity is noted to be $10.51-11.76 \mathrm{~h}$ and $11.97-12.29 \mathrm{~h}$. These timings are marked by vertical dotted lines in this figure and termed as $\delta_{1}$ and $\delta_{2}$. For events on 6 September 2017 (see Fig. 2), the EMIC wave activity is seen in $f_{1}, f_{2}$ and $f_{3}$ frequencies. The timings of the EMIC wave activity are $11.19-13.06 \mathrm{~h}$ for $f_{1}, 05.15-05.52 \mathrm{~h}, 07.42-07.68$ $\mathrm{h}, 08.09-08.77 \mathrm{~h}$ and $10.13-10.48 \mathrm{~h}$ for $f_{2}$, and $05.10-05.39 \mathrm{~h}$ for $f_{3}$ frequency ranges. It may be noted that considerably low power EMIC events, like which are marked as A, B and C in Fig. 2a, may be neglected due to choice of $-100 \mathrm{nT}^{2} / \mathrm{Hz}$ limit.

In general the EMIC wave activity can be seen for multiple time intervals on a given day. Thus, we computed the total duration of EMIC waves for each day using $T_{d}=\delta_{1}+\delta_{2}+\delta_{3}+\ldots \delta_{n}$ (in Fig. 1). It should be noted that when EMIC wave activity is seen simultaneously in two or more frequency bands (e.g., in Fig. 2, occurrence in $f_{2}$ and $f_{3}$ frequencies have overlapped), we have counted overlapping period of EMIC wave occurrence only once while computing $T_{d}$. In such cases, $T_{d} \leq \delta_{1}+\delta_{2}+\delta_{3}+\cdots \delta_{n}$. This way for each day we have also estimated the duration of EMIC wave activity. The EMIC wave durations for the examples depicted in Figs. 1 and 2 are mentioned in their respective figures.

We have divided all observational days into magnetically quiet and disturbed based on the geomagnetic activity index $A p$ (Menvielle and Berthelier 1991). A given day is treated as magnetically disturbed if $A p$ on that day or the previous day is greater than or equal to 20 . Here, we have checked the magnetic activity on previous day as

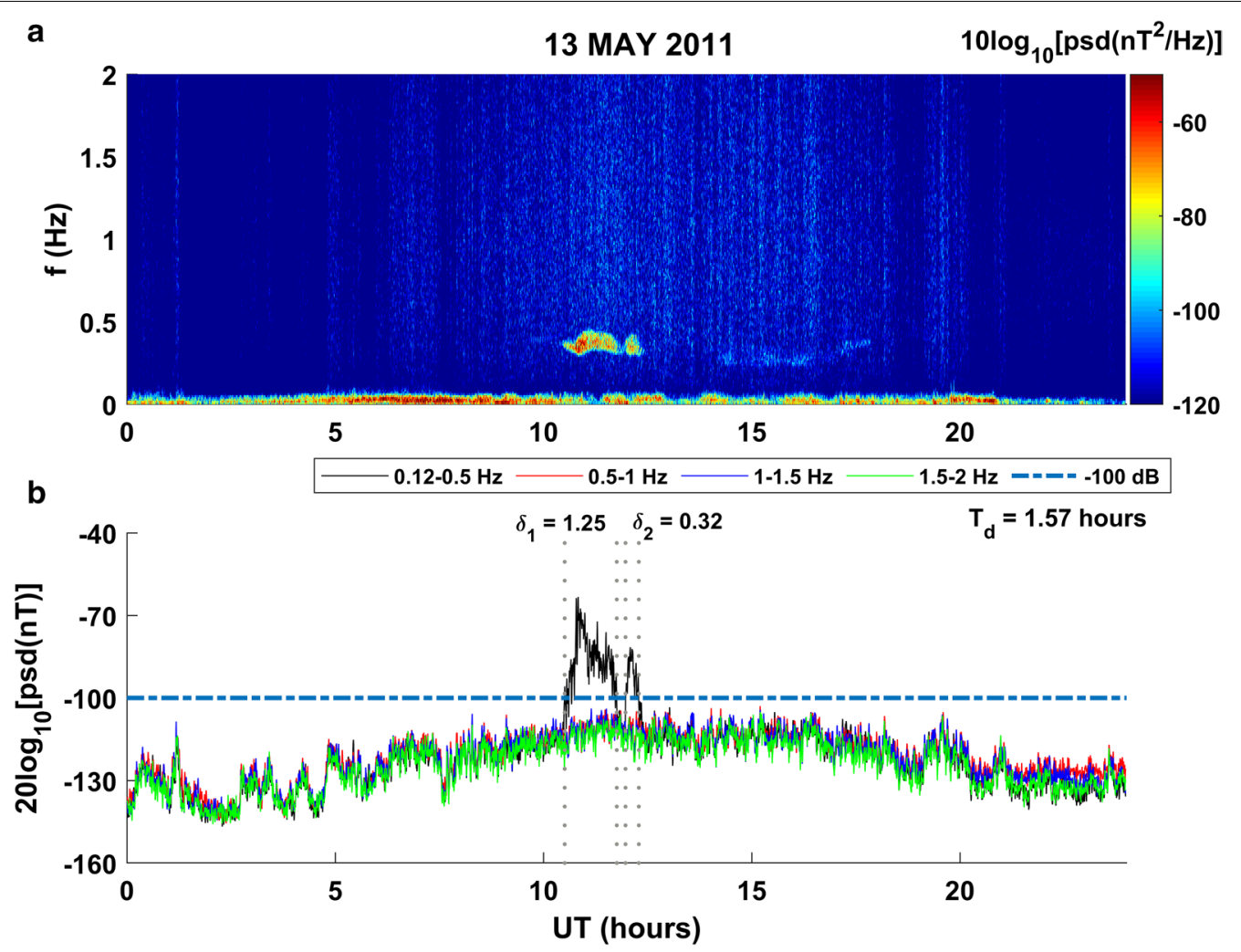

Fig. 1 a The spectrogram of total magnetic field variation, and $\mathbf{b}$ corresponding plot of averaged powers for different frequency bins are depicted as a function of universal time (UT $=\mathrm{LT}-0.77 \mathrm{~h}$ ) for EMIC wave activities observed on 13 May 2011. The intervals of EMIC wave activities are indicated in the lower panel and they are marked with black dotted vertical lines. $\delta_{1}$ and $\delta_{2}$ represent the durations of occurrences of EMIC waves in frequency bin $f_{1}(0.12-0.5 \mathrm{~Hz})$. The total EMIC wave duration for this day is $1.57 \mathrm{~h}$ 


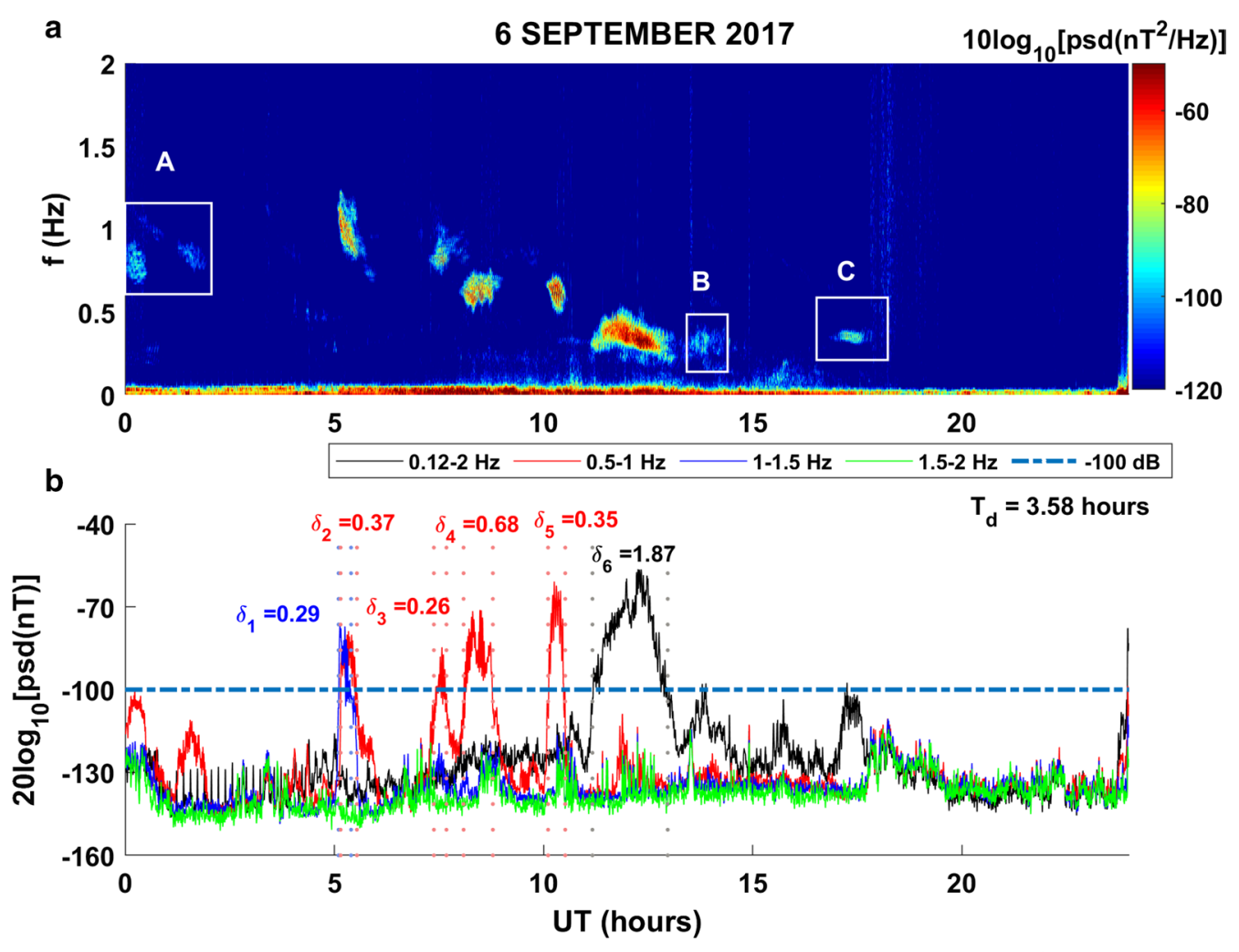

Fig. 2 a The spectrogram of the total magnetic field variation, and $\mathbf{b}$ corresponding plot of averaged powers for different frequency bins are depicted as a function of universal time (UT $=\mathrm{LT}-0.77 \mathrm{~h}$ ) for EMIC wave activity observed on 6 September 2017. The intervals of EMIC wave activity are mentioned in the lower panel and they are marked with black, red and blue dotted vertical lines for $f_{1}, f_{2}$ and $f_{3}$ frequency bins, respectively. The $\delta_{1-6}$ represent the durations of EMIC waves in these three frequency bins. The total EMIC duration for this day is $3.58 \mathrm{~h}$. The white boxes marked by letters $A, B$ and $C$ represent EMIC wave events with very low power

well, because the ambient ionospheric parameters vary on a larger time scales (a few to tens of hours) in response to the magnetic activity (Scherliess and Fejer 1997; Kakad et al. 2017). The EMIC waves generated in the Earth's inner magnetosphere at low-latitude region travel along the magnetic field lines and propagate through ionospheric duct to reach the ground stations. Thus, it is important to consider the persistence of effects in the ionosphere linked to magnetic activity.

\section{Results}

\section{EMIC wave occurrence and solar cycle dependence}

In this section, we discuss the overall occurrence scenario of EMIC waves at Maitri. Out of 2557 days, the data were available for 2367 days, of which 1964 were quiet and 403 were disturbed days. There was no data for 190 days (i.e., $7.43 \%$ of the available data). As the data loss is significantly small, we have neglected the periods with no data and treated all available observation periods as the total database (i.e., 100\%). The overall percentage of EMIC wave occurrence is found to be $5.57 \%$ which corresponds to $3166.5 \mathrm{~h}$. As mentioned earlier, the observation period 2011-2017 has fairly good coverage of ascending and descending phase of solar cycle 24 . The peak of solar cycle 24 was in April 2014. We noted that although observational period during ascending and descending phase is nearly the same (i.e., 40 and 44 months, respectively), the percentage occurrence of EMIC waves during these two phases are different. During ascending phase the EMIC wave occurrence is $4.08 \%(\approx 1058.2 \mathrm{~h})$, whereas in descending phase it is $6.83 \%(\approx 2108.3 \mathrm{~h})$. It implies that during the descending phase the occurrence of EMIC waves is nearly 1.7 times of its occurrence during the ascending phase of solar cycle 24 . This tendency is consistently seen for both quiet and disturbed days. For ascending and descending phases, the percentage occurrence of EMIC waves is summarized in Table 1, separately for quiet and disturbed days.

If we visualize the distribution of occurrence of EMIC waves in time domain for the years 2011-2017 all together, then it appears as shown in Fig. 3. Here, all EMIC wave events have been considered, irrespective of quiet or disturbed day or frequency bin. In this figure, we have plotted the occurrence/non-occurrence of EMIC 
Table 1 Overall occurrence characteristics of EMIC waves in ascending and descending phases of solar cycle for quiet and disturbed days during 2011-2017

\begin{tabular}{|c|c|c|c|c|}
\hline \multicolumn{2}{|c|}{ Ascending phase } & \multicolumn{2}{|c|}{ Descending phase } & \multirow{2}{*}{$\begin{array}{l}\text { Total } \\
\text { Obs. }=2367 \text { days }\end{array}$} \\
\hline \multicolumn{2}{|c|}{ Obs. $=1080$ days } & \multicolumn{2}{|l|}{ Obs. $=1287$ days } & \\
\hline \multicolumn{2}{|c|}{ Occ. $=1058.2 \mathrm{~h},(4.08 \%)$} & \multicolumn{2}{|c|}{ Occ. $=2108.3 \mathrm{~h},(6.83 \%)$} & Occ. $=3166.5 \mathrm{~h},(5.57 \%)$ \\
\hline Quiet & Disturbed & Quiet & Disturbed & \\
\hline Obs $=939$ days & Obs $=141$ days & Obs. $=1025$ days & Obs. $=262$ days & Obs $=2367$ days \\
\hline Occ. $=913.0 \mathrm{~h}$ & Occ. $=145.2 \mathrm{~h}$ & Occ $=1688.8 \mathrm{~h}$ & Occ. $=419.5 \mathrm{~h}$ & Occ $=3166.5 \mathrm{~h}$ \\
\hline$(3.52 \%)$ & $(0.56 \%)$ & $(5.47 \%)$ & $(1.36 \%)$ & $(5.57 \%)$ \\
\hline
\end{tabular}

Observations are mentioned in days, and EMIC wave occurrence is mentioned in hours

waves for each day of an individual year as a function of time. The average value of solar flux for each year is mentioned on the right hand side. We have plotted the data with a resolution of 5 min on $x$-axis and 1 day on $y$-axis. In this figure, the cyan color shows no occurrence of EMIC waves, the brown patches present the data loss, and the black patches show the presence of EMIC wave activity in either of the frequency bins. It is clearly evident that the EMIC wave occurrence is considerably higher after 2014, a period of high solar activity (average solar flux, $\left\langle\Phi_{s}\right\rangle=145.9$ ). For 2011-2017, the year-wise percentages of EMIC wave occurrence are $2.84 \%, 4.58 \%$, $5.18 \%, 2.96 \%, 6.06 \%, 7.23 \%$ and $9.72 \%$, respectively. In terms of total duration, the EMIC wave activity for the respective year is seen for 198.25, 397.83, 383.17, 259.00, $497.58,602.17$ and $828.41 \mathrm{~h}$. This indicates significant increase in EMIC wave activity during 2015-2017, which happens to be the descending phase of solar activity. Another feature, which is evident in Fig. 3 is that the occurrence of EMIC waves is favored during a particular time of the day and this feature is examined and details are given in the section "Seasonal and local time dependence".

We have also examined the monthly percentage occurrence of EMIC waves for 2011-2017. Figure 4a shows the daily variation of F10.7 cm solar flux (blue) superimposed with 13-monthly smooth average solar flux (red), and Fig. $4 \mathrm{~b}$ shows the monthly percentage of duration of EMIC wave activity (blue bars). Its scale is mentioned on left-side $Y$-axis. For each month, the actual duration (in hours) is marked by red dots in Fig. $4 \mathrm{~b}$ and its scale is mentioned on the right-side $Y$-axis. Months for which data loss is more than $30 \%$ are marked by yellow bars. For these 5 months the data loss is between 60 and 100\%. A vertical dashed line marks April 2014, a month for which peak sunspot number is observed in solar cycle 24. A careful examination of Fig. 4 suggests that the EMIC wave occurrence is significantly enhanced in the descending phase of solar cycle. If we count the total number of hours with EMIC wave activity in ascending and descending phase of solar cycle, it comes out to be $1058.2 \mathrm{~h}$ and $2108.3 \mathrm{~h}$, respectively. It means that in $5.58 \%$ of total EMIC occurrence during SC $24,1.87 \%$ and $3.71 \%$ are, respectively, contributed by the ascending and descending phases of the solar cycle.

Some of the earlier studies have shown that the EMIC wave activity observed in space (AMPTE/CCE satellites) does show a dependence on the level of solar activity (Mursula et al. 1996). These authors have reported that Pc1 pulsations occur considerably more often during the solar minimum than during the solar maximum periods. If we look at the statistics at Maitri then one can note that in the initial phase of solar cycle (first half of ascending phase 2011-2012, solar flux 113) and in the initial part of descending phase $(2015$, solar flux $\sim 118)$ the solar flux values are nearly same. However, the percentage occurrence of EMIC waves for both these periods are not same; they are $2.84 \%(\sim 198.25 \mathrm{~h})$ and $6.06 \%(\sim 497.58$ h), respectively. If we assume that the EMIC wave occurrence is solely controlled by the solar flux, then we must have observed nearly same percentage of EMIC waves occurrence for these two periods, but we do not observe such behavior at Maitri. In fact in the descending phase (i.e., 2015 onwards) the EMIC occurrence is consistently high ( $>6 \%$ ), and hence cannot be simply attributed to the solar flux. To understand this dependence, we have examined interplanetary parameters, which are discussed in section "Role of solar wind parameters" .

\section{Seasonal and local time dependence}

In this section, we examine the seasonal percentage occurrence of EMIC waves separately for ascending and descending phases of the solar cycle. Maitri is situated in the southern hemisphere, and during November, December, January and February it experiences the summer, whereas it is winter during the rest of the months. For summer, we combined January-February and November-December (NDJF), whereas for winter 


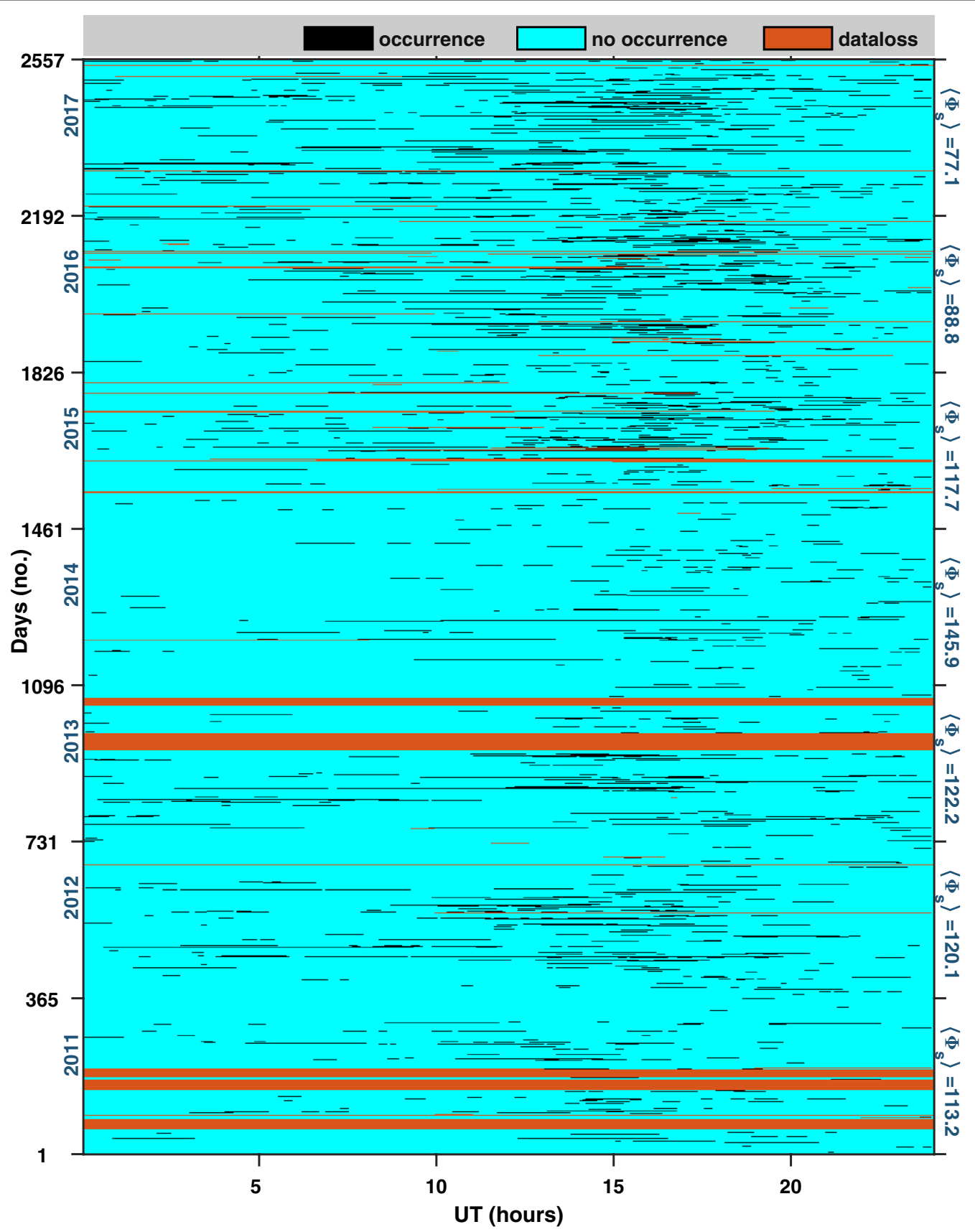

Fig. 3 Daily distribution of EMIC wave occurrence in time domain (0-24 UT h) for years 2011-2017. Each black, cyan, and brown color patch represents the occurrence, no occurrence of EMIC waves, and data loss, respectively. For each year the average value of solar flux $\left\langle\Phi_{s}\right\rangle$ is given on the right-side. Here, $\mathrm{UT}=\mathrm{LT}-0.77 \mathrm{~h}$. The resolution of plot is $5 \mathrm{~min}$ on $\mathrm{x}$-axis and 1 day on $y$ axis

we combined months from March to October (MAMJJASO), and calculated the percentage of EMIC wave occurrence separately for the quiet and disturbed days, which is mentioned in Fig. 5. The upper and lower panels in Fig. 5 correspond to EMIC wave occurrence during the ascending and descending phases of solar cycle, respectively. For quiet days, both ascending (Fig. 5a) and descending (Fig. 5b) phases show a tendency of slightly higher occurrence of EMIC waves during winter as compared to summer. Overall, for quiet days in ascending (descending) phase the EMIC wave occurrence during winter and summer are $5.02 \%$ and $2.54 \%$ (7.65\% and $5.23 \%$ ), respectively. It suggests that there is a tendency of higher occurrence of EMIC waves on ground during 


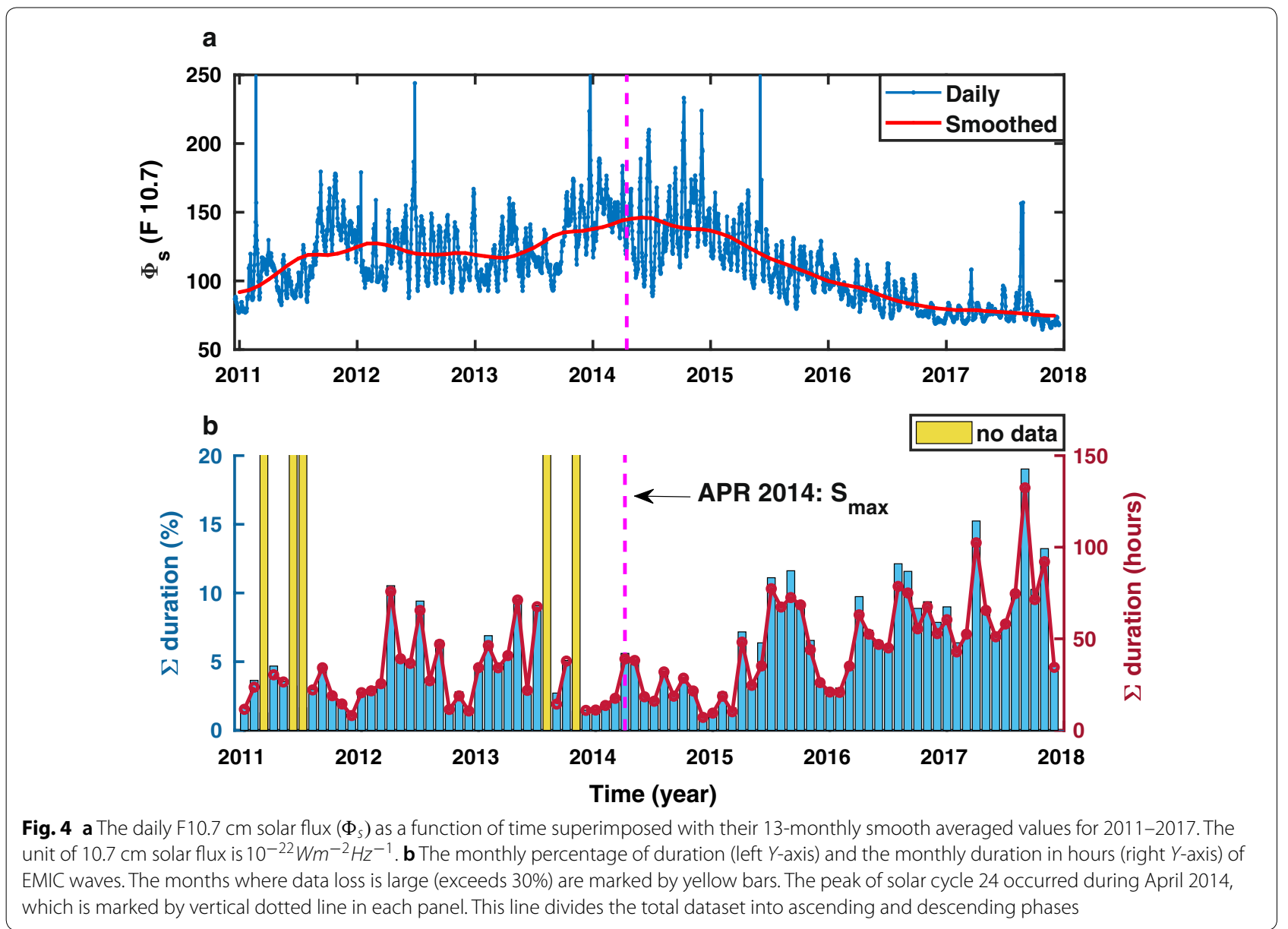

winter season. For disturbed days, this tendency is not that clear (see Fig. 5c, d) for both ascending and descending phases of SC. Such seasonal trends are not reported by any satellite-based study. The key to the observed seasonal dependence of EMIC wave occurrence might be linked to the propagation of these waves from their generation region to the ground through the ionospheric ducts. It is known that EMIC wave power undergoes attenuation during its propagation, and this attenuation is significant for higher frequencies of the EMIC wave (Kim et al. 2011). EMIC wave can undergo attenuation when they propagate along the magnetic field line away from the source region and also during their propagation through ionospheric duct after their arrival at the footprint of the magnetic field line in the ionosphere. Among both, the later attenuation is significant and it is dependent on wave propagation direction, wave frequency, and ionospheric conditions (Kim et al. 2011). Thus, we examined the ionospheric conditions for 2011-2017, which are elaborated in "Discussion" section. The seasonal tendency of EMIC waves on ground have been suggested earlier by Popecki et al. (1993).
In order to examine the observed diurnal pattern in ground EMIC wave occurrence (see Fig. 3) in details, we estimated the distribution of occurrence of EMIC waves in local time for quiet and disturbed days during the ascending and descending phases of the solar cycle. For this purpose, we first separated the data into mentioned categories and then looked into the occurrence of EMIC waves within a time interval of $5 \mathrm{~min}$. For example, we have total 939 quiet days in the ascending phase of solar cycle, so we created a matrix of 939 days by 288 grids in the time domain. For each 5-min time grid, we counted days for which occurrence was seen during that $5 \mathrm{~min}$. If $n_{i}$ is the number of count for $i$ th time grid then $y_{i}=n_{i} \times 5 / 60$ gives total duration of EMIC wave occurrence in hours for that $i$ th time grid under that category. Then we obtained probability distribution function $(p d f)$ for EMIC wave occurrence in local time by dividing duration of EMIC waves at $i$ th time grid by total duration of EMIC wave occurrence for that category (i.e., $\left.p d f_{i}=y_{i} / \sum y_{i}\right)$, which will give $\sum p d f=1$. The probability distribution function of the local time distribution of EMIC wave occurrence is shown in Fig. 6 for (a) 


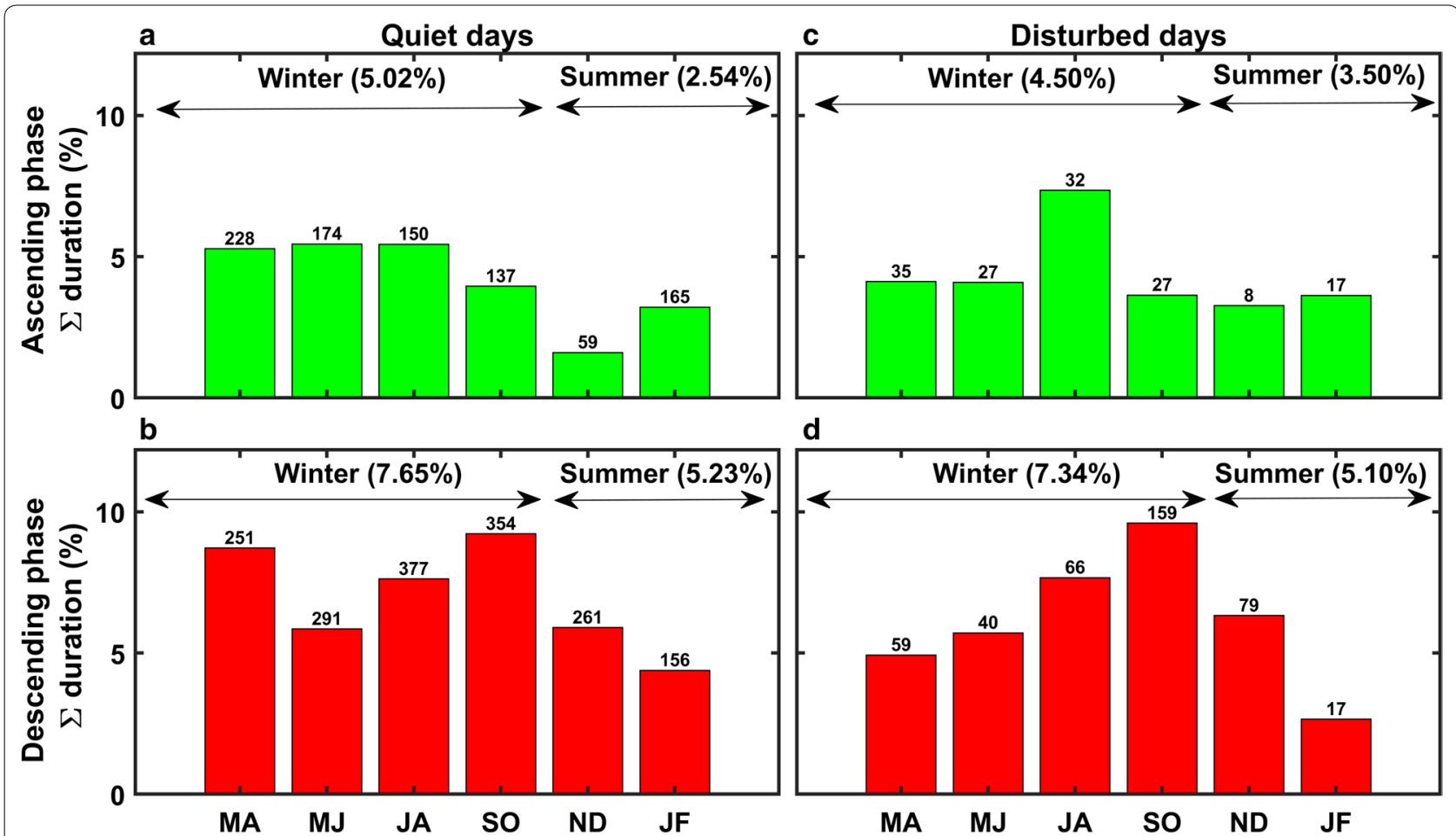

Fig. 5 Quiet time $(\mathbf{a}, \mathbf{b})$ and disturbed time $(\mathbf{c}, \mathbf{d})$, respectively, represent the seasonal percentage occurrence of EMIC waves for ascending (upper panels) and descending (lower panels) phases of the solar cycle. The duration of EMIC wave occurrence falling under each category is mentioned on each bar (in hours)

ascending phase and (b) descending phase. Blue and red color curves are for quiet and disturbed days, respectively. The most apparent feature of Fig. 6 is the enhanced probability around 11-20 UT (11.7-20.7 LT hours) for quiet days and it is consistent for both ascending and descending phases of the solar cycle. On disturbed days, the peak narrows down and it is pronounced during 13-19 UT (13.7-19.7 LT). Irrespective of quiet or disturbed days, the likely occurrence of EMIC waves in afternoon to dusk sector is evident at ground station Maitri.

There are earlier studies using satellite observations that reported the peak in EMIC wave occurrence around afternoon-dusk sector (Meredith et al. 2003; Clausen et al. 2011). Recent study using Van Allen Probe observations suggests that the majority of the EMIC waves are located in the afternoon (12-18 MLT) sector (Noh et al. 2018). Fu et al. (2018) have looked into the multi-band EMIC waves observed by Van Allen Probe and reported the enhanced EMIC wave activity in the dayside magnetosphere. Park et al. (2016) used a higher resolution data of GOES and showed that the peak occurrence of EMIC waves is at 15-16 MLT. On ground, similar local time tendency is reported for EMIC waves at high-latitude stations $(L>6)$ (Posch et al. 2010). All these mentioned studies support the higher probability of EMIC wave occurrence during afternoon-dusk sector. One common phenomenon, which is likely in the afternoon-dusk sector is the occurrence of plasmaspheric plumes/bulges (Moldwin et al. 2004). Plasmaspheric plumes/bulges are the high density, cold plasma structures extending from plasmasphere, to higher $L$-shells. Fraser and Nguyen (2001) reported peak occurrence of EMIC waves close to afternoon-dusk sector using CRRES satellite observations and they noticed that afternoon wave events are seen in a background plasma density of $4-300 \mathrm{~cm}^{-3}$. The presence of such higher densities suggest an association with the plasmaspheric plume/bulge and they are possibly detached plasma regions. Another point is hot ions entering from magnetospheric tail drift westward, where they can encounter a cold plasma population in the plasmaspheric plumes/bulge to provide favorable condition for the triggering of EMIC waves. Global simulation carried out for storm time conditions suggest that the largest wave growth is expected in the post-noon local time (Jordanova et al. 2008).

Usanova et al. (2013) have used Cluster satellite measurements of EMIC waves in plasmaspheric plumes to address the question whether plumes are important for the EMIC wave generation or not. In their study, it is 


\section{a Ascending phase}

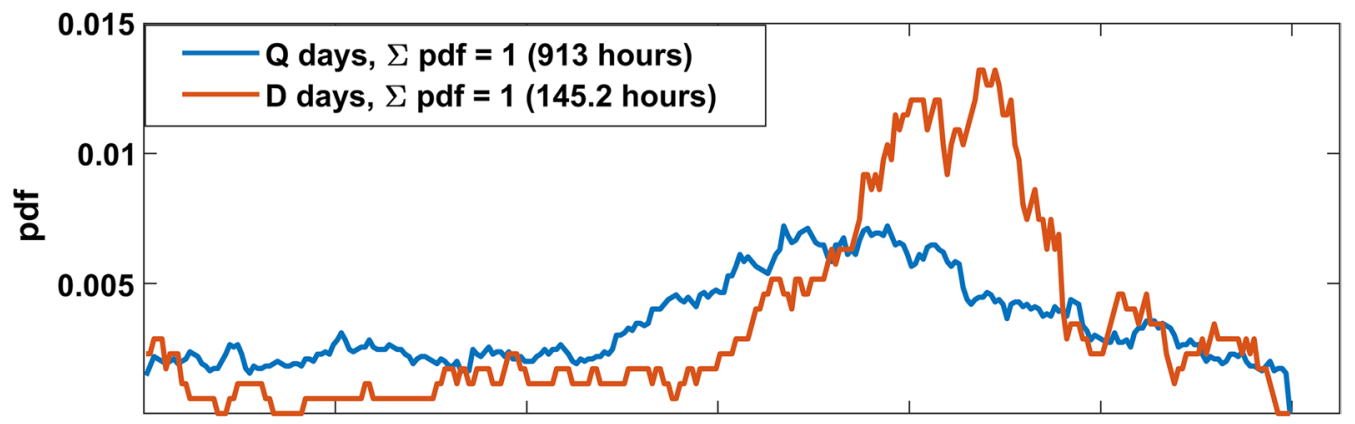

b Descending phase

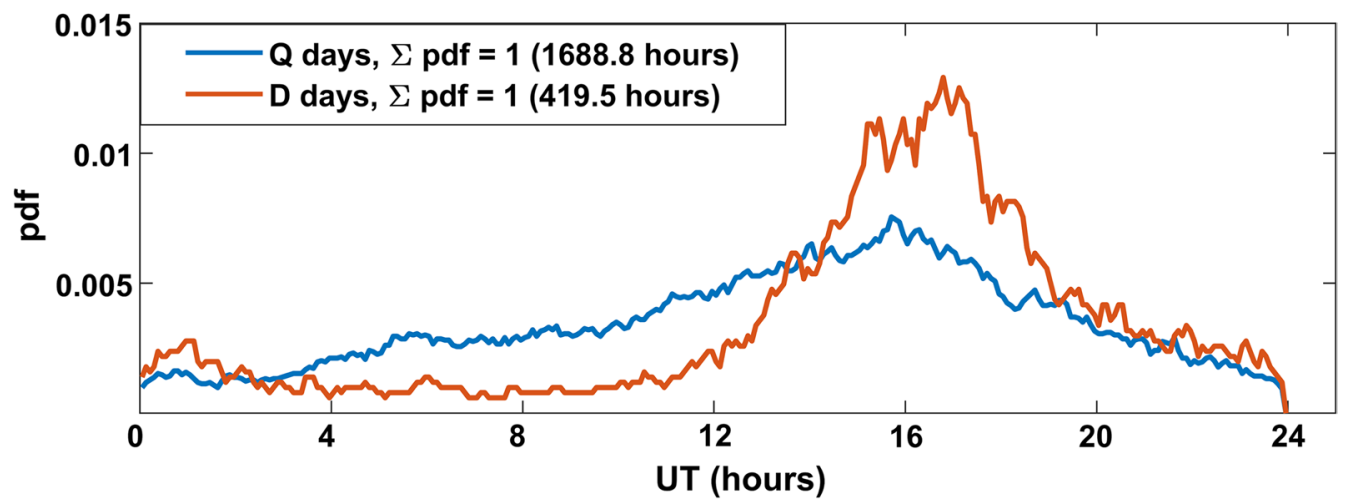

Fig. 6 Local time distribution of occurrence of EMIC waves is shown for a ascending phase and $\mathbf{b}$ descending phase. The blue and orange-colored curves represent the quiet days and disturbed days, respectively. The summation of pdf gives 1, which corresponds to the total number of EMIC wave occurrence in hours for respective bins

shown that EMIC waves were observed for 106 out of 993 plume crossings, which is only $11 \%$. It means plasmaspheric plumes are not potentially affecting the EMIC wave occurrence and the same was concluded by Usanova et al. (2013). In fact, the existence of a plasmaspheric plume is not a sufficient condition for EMIC wave excitation. Anisotropic ring current ion distributions (or hot proton population) are needed as well (Jordanova et al. 2008). The recent study by Saikin et al. (2018) have shown that there is an asymmetric distribution of the hot proton in magnetic local time (MLT) within the inner magnetosphere $(L<7)$ and the asymmetry parameter $A_{h p}$ for the hot proton varies from 0.81 to 1 in the dawnsector to $0.62-0.81$ in the dusk sector. The parameter $A_{h p}$ denotes the anisotropy in hot proton population and is defined as $A_{h p}=T_{\perp} / T_{\|}-1$. It is known that the positive wave growth for EMIC waves can be obtained only if $T_{\perp}>T_{\|}$(i.e., $A_{h p}>0$ ). These authors have also noted that the values of $A_{h p}$ are found to be smaller during the EMIC wave activity that is similar to the values that are observed in dusk sector. Theoretical study by Omura et al. (2010) has shown that hot proton density $\left(n_{h}\right)$ plays an important role in deciding the nonlinear growth of EMIC wave rising tone emissions. Thus, the possible reason for the local time dependence of EMIC wave occurrence could be governed through the hot proton population, which is required for the EMIC wave generation in the dusk-sector.

\section{EMIC wave durations}

In section "Data analysis and EMIC wave identification", we have explained the method to estimate the daily duration $T_{d}$ of EMIC waves for a given day. The duration $T_{d}$ represents the total time for which EMIC wave activity is seen and this activity may be associated with either continuous or discrete time intervals of EMIC waves. In our database, the EMIC wave duration for a given day varies from $5-1015$ mins. To examine the distribution of durations of EMIC waves, we have divided the days with EMIC wave activity as (i) 5-90 mins, (ii) 90-240 mins, (iii) $240-480$ mins and (iv) $480-$ 1015 mins. This is carried out separately for quiet and disturbed days of the ascending and descending phases of solar cycle. The percentage occurrence of EMIC waves under each of these categories is shown in Fig. 7 for (a) quiet days and (b) disturbed days. A similar plot 


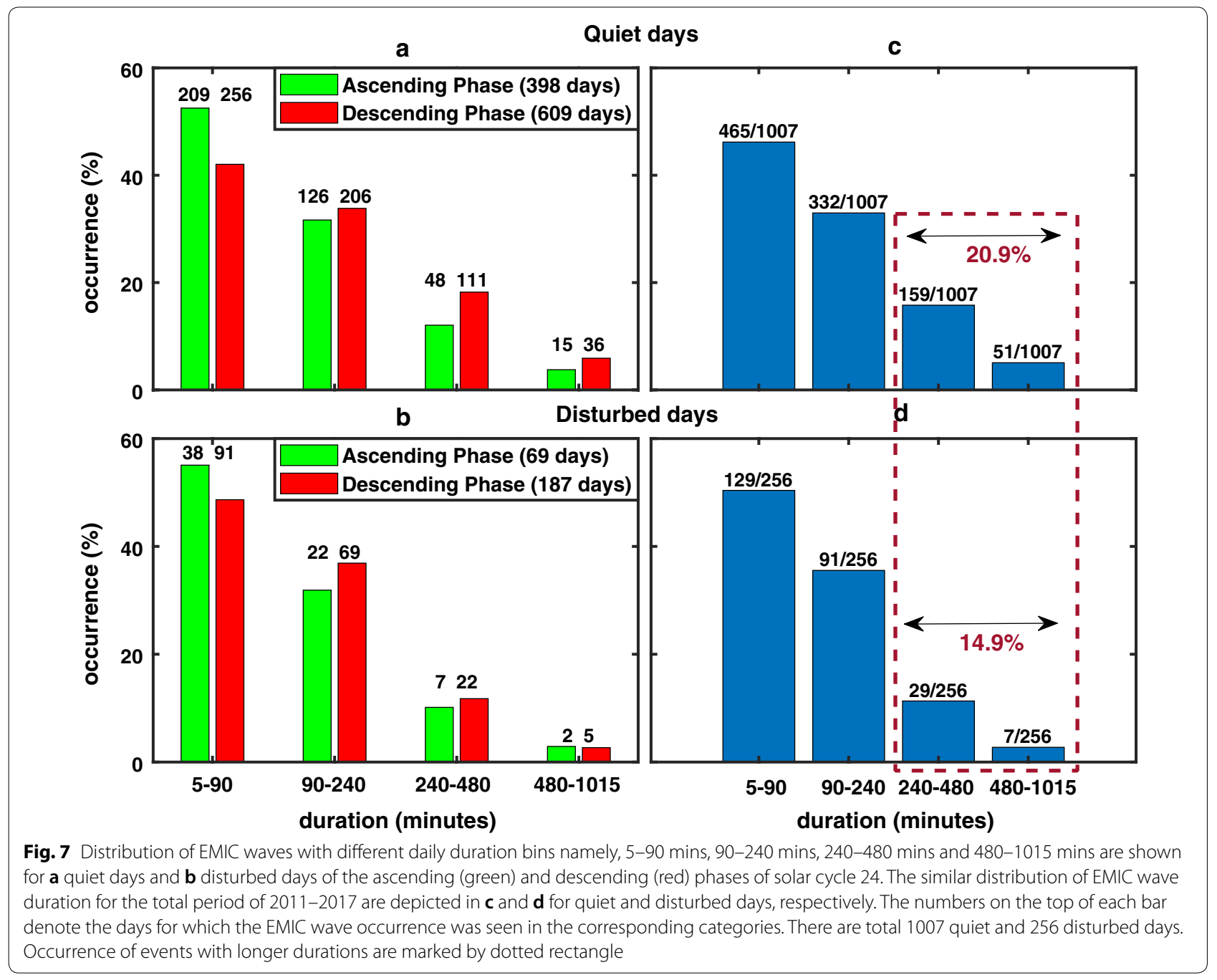

is shown in Fig. 7 for (c) quiet days, and (d) disturbed days by combining all EMIC wave occurrence during 2011-2017. We can see that the longer duration events (> 240 minutes) are prevalent on quiet days as compared to those on disturbed days (see marked portion in Fig. 7c, d), and these events are mostly contributed by the descending phase of solar cycle. Heacock (1966) examined the duration of Pc1 waves and they reported that on magnetically quiet days $\left(K_{p} \leq 3\right)$, there were longer stable bandwidth emissions which supports our results. However, we do not have any clue whether or not this tendency is associated with ambient parameters in the generation region or it has a link with EMIC wave propagation to the ground. The propagation characteristics of EMIC waves in ionospheric ducts during magnetically disturbed days will be significantly different from those during quiet days due to changed ambient ionospheric conditions. This could be one of the reasons for higher count of EMIC waves being observed on the ground at Maitri during geomagnetic quiet days.

\section{Discussion}

\section{Role of solar wind parameters}

It may be noted that factors favorable for generation of the EMIC waves may be directly or indirectly governed through the solar wind conditions. We have analyzed the interplanetary solar wind parameters during 2011-2017. The solar wind parameters such as density, velocity, and temperature at the Earth's bow-shock nose are taken from OMNIWeb for this period. The solar wind dynamic pressure is calculated using $P=n_{i} m_{i} V^{2}$ (here, $n_{i}=$ density of ions, $m_{i}=$ mass of ions and $V=$ solar wind velocity), which is equivalent to the twice of the solar wind kinetic energy density (i.e., $P=2 E_{K E}$ ). We separated the ascending and descending phase solar wind parameters and obtained their distribution functions. In Fig. 8a-d, the distributions of solar wind 


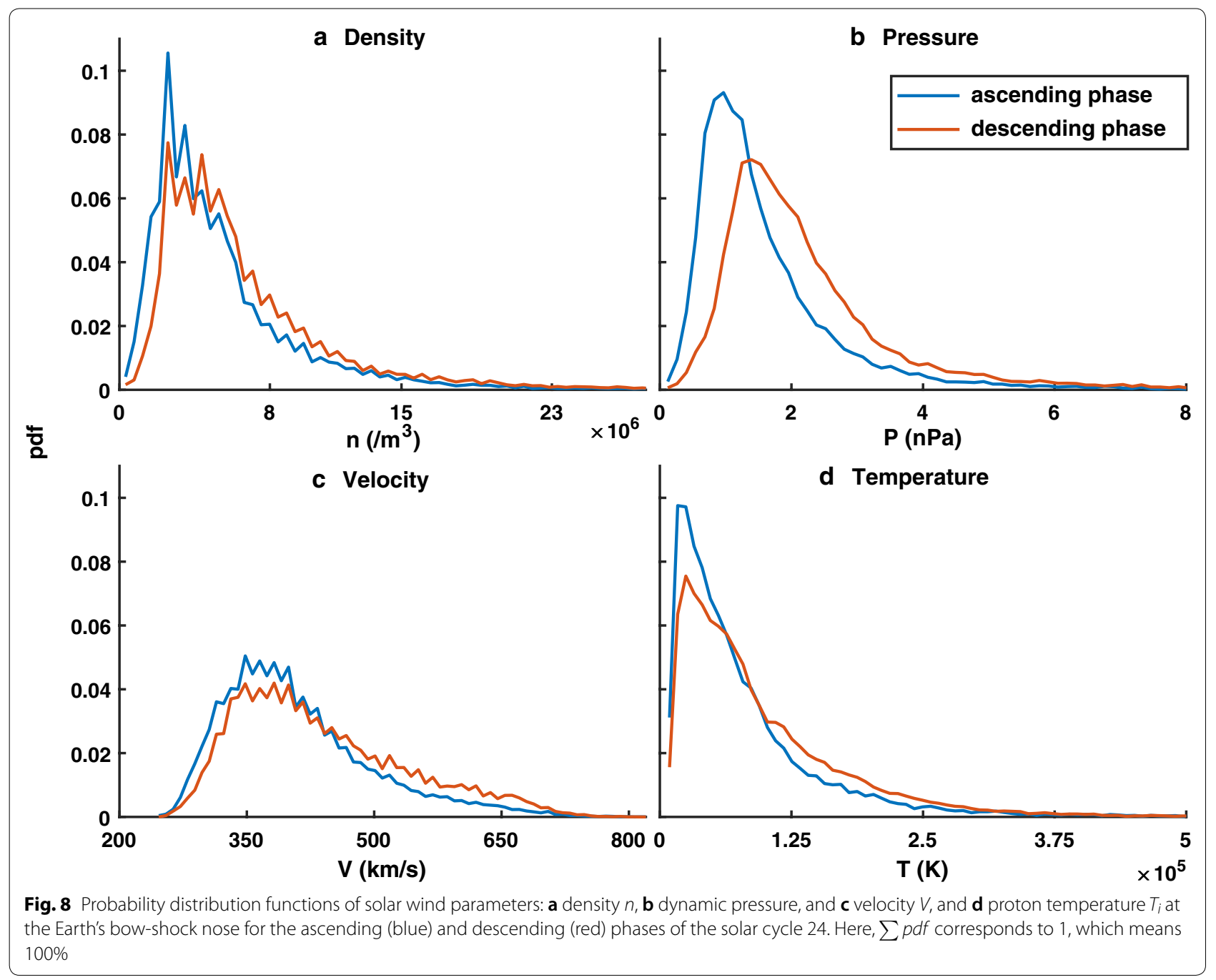

density $\left(/ \mathrm{m}^{3}\right)$, dynamic pressure $\left(J / \mathrm{m}^{3}\right.$ or $\left.\mathrm{nPa}\right)$, velocity $(\mathrm{km} / \mathrm{s})$, and temperature $(K)$ are shown, respectively. We observe that the distributions of solar wind velocity and dynamic pressure are considerably different during descending phase as compared to the ascending phase of solar cycle. The peak in their distributions shift towards higher values and also the distributions are broadened for the descending phase. We can compare these distributions with the Maxwell-Boltzmann distribution. A shift in peak towards higher value shows that the most probable value of that parameter has increased and broadening in the distribution implies increase in the average value. From Fig. 8, it is evident that the average value of dynamic pressure is higher during the descending phase of solar cycle. This increase in dynamic pressure could possibly be responsible for the higher occurrence of EMIC waves during the descending phase. Further to verify this tendency, we have checked the correlation between monthly percentage occurrence of EMIC wave duration with monthly averaged solar wind dynamic pressure. Figure 9 shows the monthly EMIC wave occurrence as a function of monthly averaged value of dynamic pressure. It is evident from the figure that these two parameters show a positive correlation $(r=0.43)$, which is based on 76 points and it is statistically significant (> 95\%). There is likely tendency of increase in EMIC wave occurrence during the periods of higher solar wind dynamic pressure.

Satellite studies have also demonstrated the role of solar wind pressure in triggering of EMIC waves (Usanova et al. 2012). Also, even with a modest pressure pulse EMIC wave can be generated in the Earth's magnetosphere (Anderson and Hamilton 1993; Kakad et al. 2019a). The spatial magnetic field gradient $(\partial B / \partial h)$ is an important parameter that determines the threshold amplitude $\left(B_{t h}\right)$ required for the triggering of EMIC 


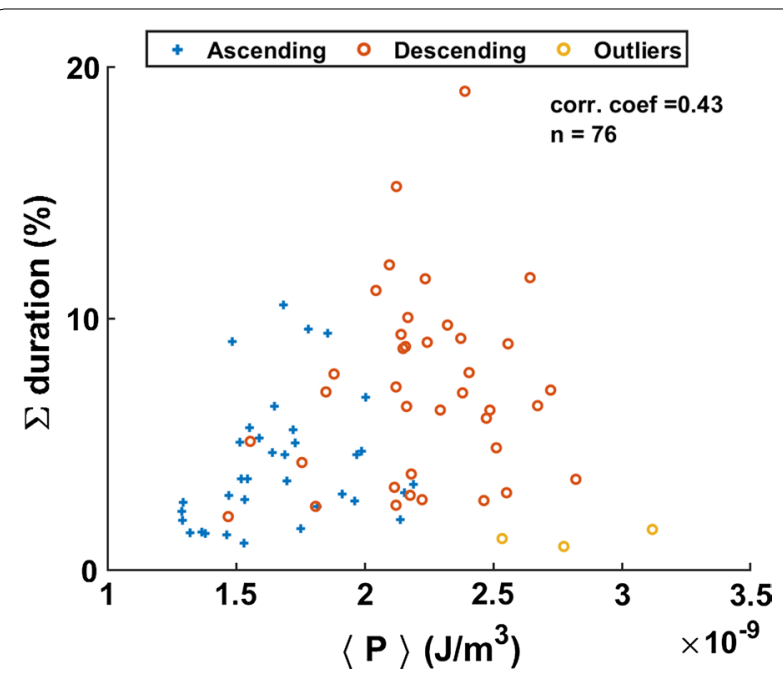

Fig. 9 Monthly percentage of duration of EMIC waves as a function of monthly averaged value of solar wind dynamic pressure, which is equivalent to the twice of solar wind kinetic energy density $\left(P=2 E_{k e}\right)$ at the Earth's bow-shock nose. The correlation coefficient between them is mentioned in the plot

waves (Omura et al. 2010). Reduced values of $\partial B / \partial h$ can decrease the threshold amplitude $B_{t h}$ and assist the triggering of EMIC waves in the generation region. Increase in dynamic pressure can provide such conditions by compressing the dayside magnetosphere. Thus, increased solar wind dynamic pressure can modify temperature anisotropy of hot protons and magnetic field gradient in such a way that it facilitates the generation of EMIC waves in the inner magnetosphere.

Since, the EMIC waves are also generated on night-side (Fig. 6) and in absence of any pressure pulse, the solar wind dynamic pressure is not the only source for the triggering of EMIC waves. Another source of instability can be provided by the ions (energies $\sim 10-100 \mathrm{keV}$ ) entering the inner magnetosphere during substorm-injection. Remya et al. (2018) have studied EMIC waves which occurred in absence of any storm or compression of magnetosphere and highlights the role of substorm-injected ions for the generation of EMIC waves.

\section{Ionospheric conditions}

To understand the seasonal (winter and summer) difference in the EMIC wave occurrence, we looked into the ionospheric densities and conductivities for 2011, 2014, and 2017, which, respectively, correspond to moderate, high, and low solar activity periods. We chose these years because the year 2011 lies in the ascending phase of solar cycle $\left(\left\langle\Phi_{s}\right\rangle=113\right), 2014$ is the year when the peak in solar activity occurred $\left(\left\langle\Phi_{s}\right\rangle=146\right)$ and the year 2017 lies in the declining phase of the solar cycle $\left(\left\langle\Phi_{s}\right\rangle=77\right)$.
It may be noted that we do not have any direct measurement of ionospheric density at the Maitri station. Hence, we cannot compare individual days to quantify the differences in the electron density on EMIC and non-EMIC days. By using model data we can certainly discuss and speculate the role of ionosphere to understand the seasonal tendencies in the EMIC wave occurrence. The ionospheric densities used in this analysis are obtained from the IRI model for the observation station, whereas conductivities are obtained from the ionospheric conductivity model available at WDC Kyoto. From this model, we have obtained the Hall conductivity $\left(\sigma_{H}\right.$, perpendicular to both ambient zonal electric and magnetic field). Figure $10 \mathrm{a}-\mathrm{c}$ shows the annual variation of electron density $\left(/ \mathrm{m}^{3}\right)$ as a function of time (UT) at $100 \mathrm{~km}$ altitude for 2011, 2014 and 2017, respectively, whereas (d-f) shows the electron density $\left(/ \mathrm{m}^{3}\right)$ as a function of time (UT) at $200 \mathrm{~km}$ altitude for 2011, 2014, and 2017, respectively. In Fig. $10 \mathrm{~g}-\mathrm{i}$, the annual variation of Hall conductivity $(S / m)$ as a function of altitude at 14.15 UT hours for 2011, 2014, and 2017 is plotted. Figure 10 indicates that the electron density and Hall conductivity are lower during the winter as compared to the summer. The solid and dotted white lines represent averages of corresponding parameters for the winter and summer, respectively. The average maximum conductivities (at $100 \mathrm{~km}$ ) and electron density (at $100 \mathrm{~km}$ and $200 \mathrm{~km}$ ) are approximately 2.3 and 1.5 times higher for the summer as compared to those during winter season. The property of the medium through which the wave propagates can affect wave propagation by altering their amplitude, speed, polarization, etc. The skin depth of a wave in a medium, i.e., the depth by which the amplitude of the wave reduces to $1 / e$, is inversely proportional to the conductivity of the medium (Griffiths 2005). For summers, when the value of the conductivity is high, the skin depth of the medium is low and the waves gets damped at shorter distances. Hence, the transionospheric EMIC wave power can experience greater attenuation when the ionospheric conductivity is higher. Ionosphere is the dispersive medium, and wave frequency, ion-neutral collisions, electron density, ambient magnetic field decide the refractive index $(\eta)$ as given by the Appleton Hartree equation (Davies 1990). In the equation, the imaginary part of the refractive index, i.e., $\chi$, controls the wave damping. According to our calculations of refractive index for different seasons, $\chi_{\text {summers }}$ is more than double of $\chi_{\text {winters }}$ at an altitude of $100-150 \mathrm{~km}$. Combination of both these parameters i.e., higher electron density and conductivity can affect the wave power and their higher values damp it significantly.

The ionospheric electron density and conductivity have no role to play in generation mechanism of EMIC waves. Nevertheless, they can definitely control the wave 


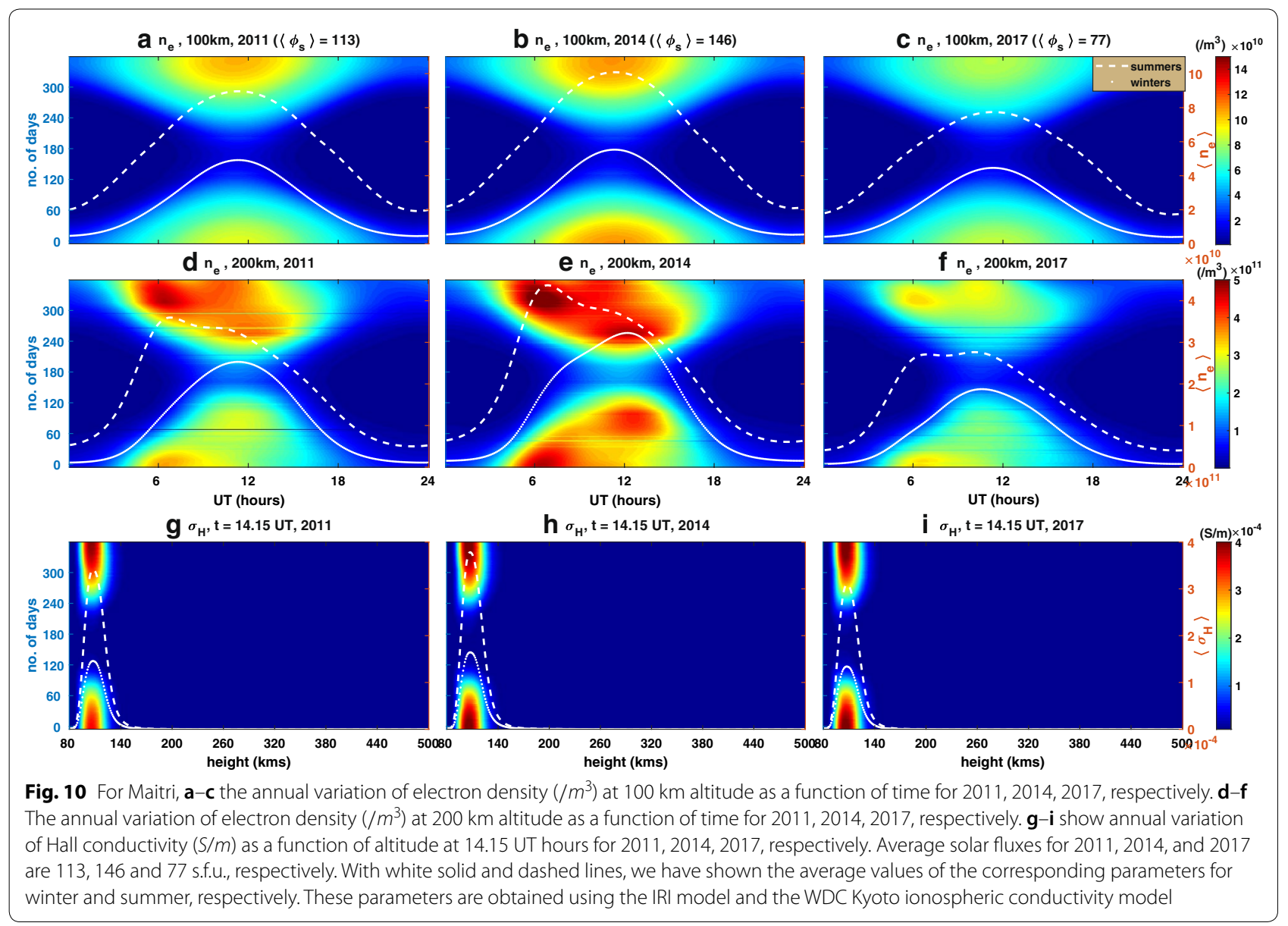

propagation to the ground through the ionosphere. The heavy ion population and concentration ratio also affect the propagation of these waves. It has been established that the ground observation is only possible due to polarization reversal, tunneling and mode conversion of the wave (Johnson and Cheng 1999). Using 2-D hybrid code simulation, $\mathrm{Hu}$ et al. (2010) have shown the wave tunneling for small concentrations of heavy ion densities. Kim and Johnson (2016) have shown the complexities involved in the EMIC wave propagation by using a full wave simulation model and have suggested that such heavy ion concentrations are in fact necessary for the EMIC wave propagation to the ground. We need modeling efforts for better understanding of the EMIC wave propagation from the source region to the ionosphere including realistic ionospheric conditions.

\section{Summary}

In the present study, the characteristics and occurrence of EMIC waves have been investigated for quiet and disturbed days during a period of 2011-2017, which covers fairly good period of the ascending and descending phases of the present solar cycle 24. The EMIC wave observations from the Indian Antarctic station, Maitri have been used. Overall statistics of EMIC wave occurrence are summarized in Table 1 . The main outcomes from the present study are listed below:

1. Overall, EMIC waves are observed for $3166.5 \mathrm{~h}$ during the 2367 days for which the data were available during 2011-2017. The occurrence of EMIC waves on magnetically disturbed days (5.83\%) is nearly same as that on quiet days (5.52\%). In terms of duration, the EMIC waves are observed for $564.7 \mathrm{~h}$ on disturbed days and for $2601.8 \mathrm{~h}$ on quiet days.

2. The occurrence of EMIC waves during ascending and descending phase of solar cycle is 4.08\% (1058.2 h) and 6.83\% (2108.3), respectively. It implies that EMIC wave occurrence during descending phase of solar cycle is 1.7 times of that during the ascending phase. It is attributed to the enhanced solar wind dynamic pressure during the descending phase of solar cycle 24. The correlation between monthly EMIC wave occurrence duration and average solar 
wind dynamic pressure is found to be 0.43 . Higher values of solar wind pressure can be a potential source for the temperature anisotropy, which is the favorable condition for generation of EMIC waves. The higher solar wind dynamic pressure can also modify spatial magnetic field gradients, which is important for the non-linear growth of EMIC wave. During descending phase, the CMEs and high speed streams (HSS) are the likely sources for the fast solar wind (Webb 1995; Richardson et al. 2000; Tsurutani et al. 2004), which can maintain the higher solar wind pressure to support the EMIC wave growth.

3. The EMIC waves observed on ground at sub-auroral Antarctic station Maitri are found to possess a seasonal dependence. On quiet days, the occurrence of EMIC waves during winter is slightly higher (i.e., $5.04 \%$ ) as compared to summer (i.e., 2.35\%) for both ascending as well as descending phases of solar cycle under investigation. This observed seasonal dependence is attributed to the low electron density and conductivity in the ionosphere as it can reduce the absorption and reflection of EMIC waves during their propagation through ionospheric ducts by modifying skin depth of wave. For disturbed days this seasonal tendency is less evident.

4. The EMIC wave observations on the ground show clear local time dependence with a peak occurrence around afternoon-dusk sector (i.e., 11.7 - 20.7 LT). Such local time dependence is reported in earlier studies using satellite observations (Meredith et al. 2003; Clausen et al. 2011; Noh et al. 2018). This behavior is attributed to the asymmetric distribution of hot proton density in the inner magnetosphere close to dusk sector (Saikin et al. 2018).

5. The longer duration (240-1015 mins) EMIC wave events are dominant on the quiet days (20.9\%) as compared to the disturbed days (14.1\%). These longduration EMIC wave events have maximum contribution from the descending phase of the solar cycle.

\begin{abstract}
Abbreviations
EMIC: Electromagnetic ion cyclotron; $\Phi_{s}$ : Solar flux; s.f.u.: Solar flux unit LT: Local time; UT: Universal time; MLT: Magnetic local time; $A_{h p}$ : Anisotropy in hot proton population; IRI: International Reference lonosphere; WDC: World Data Center; pdf: Probability distribution function; SC: Solar cycle; $\sigma_{H}$ : Hall conductivity; $\eta$ : Refractive index; $\chi$ : Imaginary part of refractive index; $S_{\text {max }}$ : Solar cycle maxima; $\boldsymbol{n}_{\boldsymbol{e}}$ : Electron density; LH: Left-handed; RH: Right-handed; J, $F, M, A, M, J, J, A, S, O, N, D$ : Initials of the months from January to December.
\end{abstract}

\section{Acknowledgements}

The work at Kyoto University is supported by JSPS KAKENHI Grant $17 \mathrm{H06140}$ We thank OMNIWeb team for interplanetary data available at http://omniw eb.gsfc.nasa.gov, NASA NGDC team for IRI model available at http://irimodel. org, WDC Kyoto for ionospheric conductivities and Ap indices available at http://wdc.kugi.kyoto-u.ac.jp/, and http://www.spaceweather.gc.ca for solar flux data. We duly acknowledge the support of R. Rawat in running the ICM experiment at Maitri.

\section{Author contributions}

AU has performed all the analysis and drafted the work. BK and AK gave overall guidance and helped in interpretations of the analyzed data. YO helped in understanding the observations based on theoretical aspect of EMIC waves. AKS is the PI for the experiment and gave fruitful suggestions on the manuscript. All authors read and approved the final manuscript.

\section{Funding}

Not applicable.

\section{Availability of data and materials}

The ICM data will be made available on http://www.iigm.res.in on request at ashwini@iigs.iigm.res.in.

\section{Ethics approval and consent to participate}

Not applicable.

\section{Consent for publication}

Not applicable.

\section{Competing interests}

The authors declare that they have no competing interests.

\section{Author details}

${ }^{1}$ Indian Institute of Geomagnetism, New Panvel, Navi Mumbai, India.

${ }^{2}$ Research Institute for Sustainable Humanosphere, Kyoto University, Kyoto, Japan.

Received: 19 November 2019 Accepted: 24 February 2020

Published online: 12 March 2020

\section{References}

Allen R, Zhang JC, Kistler L, Spence H, Lin RL, Klecker B, Dunlop M, André M, Jordanova V (2015) A statistical study of emic waves observed by cluster: 1. wave properties. J Geophys Res 120(7):5574-5592

Anderson B, Hamilton DC (1993) Electromagnetic ion cyclotron waves stimulated by modest magnetospheric compressions. J Geophys Res 98(A7):11369-11382

Anderson B, Takahashi K, Erlandson R, Zanetti L (1990) Pc1 pulsations observed by ampte/cce in the earth's outer magnetosphere. Geophys Res Lett 17(11):1853-1856

Bortnik J, Thorne R, O'Brien T, Green J, Strangeway R, Shprits Y, Baker D (2006) Observation of two distinct, rapid loss mechanisms during the 20 November 2003 radiation belt dropout event. J Geophys Res 111:A12

Carson BR, Rodger CJ, Clilverd MA (2013) Poes satellite observations of emic-wave driven relativistic electron precipitation during 1998-2010. J Geophys Res 118(1):232-243

Clausen L, Baker J, Ruohoniemi J, Singer H (2011) Emic waves observed at geosynchronous orbit during solar minimum: statistics and excitation. J Geophys Res 116:A10

Cornwall JM (1965) Cyclotron instabilities and electromagnetic emission in the ultra low frequency and very low frequency ranges. J Geophys Res 70(1):61-69

Davies K (1990) Ionospheric radio. 31, IET

Erlandson R, Zanetti L, Potemra T, Block L, Holmgren G (1990) Viking magnetic and electric field observations of pc 1 waves at high latitudes. J Geophys Res 95(A5):5941-5955

Fraser B, Nguyen T (2001) Is the plasmapause a preferred source region of electromagnetic ion cyclotron waves in the magnetosphere? J Atmos Solar Terrestr Phys 63(11):1225-1247

Fu S, He F, Gu X, Ni B, Xiang Z, Liu J (2018) Occurrence features of simultaneous $\mathrm{H}+$-and $\mathrm{HE}+$-band emic emissions in the outer radiation belt. Adv Space Res 61(8):2091-2098

Griffiths DJ (2005) Introduction to electrodynamics 
Guglielmi A, Kangas J, Kultima J, Potapov A (2005) Solar wind dependence of the pc1 wave activity. Adv Space Res 36(12):2413-2416

Heacock R (1966) The 4-second summertime micropulsation band at college. J Geophys Res 71(11):2763-2775

Hu Y, Denton R, Johnson J (2010) Two-dimensional hybrid code simulation of electromagnetic ion cyclotron waves of multi-ion plasmas in a dipole magnetic field. J Geophys Res 115:A9

Johnson JR, Cheng C (1999) Can ion cyclotron waves propagate to the ground? Geophys Res Lett 26(6):671-674

Jordanova V, Albert J, Miyoshi Y (2008) Relativistic electron precipitation by emic waves from self-consistent global simulations. J Geophys Res 113:A3

Kakad B, Surve G, Tiwari P, Yadav V, Bhattacharyya A (2017) Disturbance dynamo effects over low-latitude f region: a study by network of vhf spaced receivers. J Geophys Res 122(5):5670-5686

Kakad B, Omura Y, Kakad A, Upadhyay A, Sinha AK (2018) Characteristics of subpacket structures in ground emic wave observations. J Geophys Res 123(10):8358-8376

Kakad A, Kakad B, Omura Y, Sinha AK, Upadhyay A, Rawat R (2019a) Modulation of electromagnetic ion cyclotron waves by pc5 ulf waves and energetic ring current ions. J Geophys Res 124(3):1992-2009

Kakad B, Kakad A, Ramesh DS, Lakhina GS (2019b) Diminishing activity of recent solar cycles (22-24) and their impact on geospace. J Space Weather Space Clim 9:A01

Kangas J, Guglielmi A, Pokhotelov O (1998) Morphology and physics of shortperiod magnetic pulsations. Space Sci Rev 83(3-4):435-512

Kennel CF, Petschek H (1966) Limit on stably trapped particle fluxes. J Geophys Res 71(1):1-28

Kim EH, Johnson JR (2016) Full-wave modeling of emic waves near the he+ gyrofrequency. Geophys Res Lett 43(1):13-21

Kim H, Lessard M, Engebretson M, Lühr H (2010) Ducting characteristics of pc 1 waves at high latitudes on the ground and in space. J Geophys Res 115:A9

Kim H, Lessard M, Engebretson M, Young M (2011) Statistical study of pc1-2 wave propagation characteristics in the high-latitude ionospheric waveguide. J Geophys Res 116:A7

Lessard MR, Lindgren EA, Engebretson MJ, Weaver C (2015) Solar cycle dependence of ion cyclotron wave frequencies. J Geophys Res 120(6):4711-4718

Lorentzen K, McCarthy M, Parks G, Foat J, Millan R, Smith D, Lin R, Treilhou J (2000) Precipitation of relativistic electrons by interaction with electromagnetic ion cyclotron waves. J Geophys Res 105(A3):5381-5389

Loto'aniu T, Fraser BJ, Waters CL (2005) Propagation of electromagnetic ion cyclotron wave energy in the magnetosphere. J Geophys Res 110:A7

Mann I, Usanova M, Murphy K, Robertson M, Milling D, Kale A, Kletzing C, Wygant J, Thaller S, Raita T (2014) Spatial localization and ducting of emic waves: van allen probes and ground-based observations. Geophys Res Lett 41(3):785-792

Menvielle M, Berthelier A (1991) The k-derived planetary indices: description and availability. Rev Geophys 29(3):415-432

Meredith NP, Thorne RM, Horne RB, Summers D, Fraser BJ, Anderson RR (2003) Statistical analysis of relativistic electron energies for cyclotron resonance with emic waves observed on crres. J Geophys Res 108:A6

Moldwin M, Howard J, Sanny J, Bocchicchio J, Rassoul H, Anderson R (2004) Plasmaspheric plumes: Crres observations of enhanced density beyond the plasmapause. J Geophys Res 109:A5

Mursula K, Kangas J, Pikkarainen T, Kivinen M (1991) PC 1 micropulsations at a high-latitude station: a study over nearly four solar cycles. J Geophys Res 96(A10):17651-17661

Mursula K, Anderson B, Erlandson R, Pikkarainen T (1996) Solar cycle change of pc1 waves observed by an equatorial satellite and on the ground. Adv Space Res 17(10):51-55

Nakamura S, Omura Y, Shoji M, Nosé M, Summers D, Angelopoulos V (2015) Subpacket structures in emic rising tone emissions observed by the themis probes. J Geophys Res 120(9):7318-7330

Noh SJ, Lee DY, Choi CR, Kim H, Skoug R (2018) Test of ion cyclotron resonance instability using proton distributions obtained from van allen probe-a observations. J Geophys Res 123(8):6591-6610

Nomura R, Shiokawa K, Sakaguchi K, Otsuka Y, Connors M (2012) Polarization of pc1/emic waves and related proton auroras observed at subauroral latitudes. J Geophys Res 117:A2

Omura Y, Pickett J, Grison B, Santolik O, Dandouras I, Engebretson M, Décréau PM, Masson A (2010) Theory and observation of electromagnetic ion cyclotron triggered emissions in the magnetosphere. J Geophys Res 115:A7
Ozaki M, Shiokawa K, Miyoshi Y, Kataoka R, Connors M, Inoue T, Yagitani S, Ebihara Y, Jun CW, Nomura R et al (2018) Discovery of 1 hz range modulation of isolated proton aurora at subauroral latitudes. Geophys Res Lett 45(3):1209-1217

Park JS, Kim KH, Shiokawa K, Lee DH, Lee E, Kwon HJ, Jin H, Jee G (2016) Emic waves observed at geosynchronous orbit under quiet geomagnetic conditions $(k p \leq 1)$. J Geophys Res 121(2):1377-1390

Pickett J, Grison B, Omura Y, Engebretson M, Dandouras I, Masson A, Adrian M, Santolik O, Décréau P, Cornilleau-Wehrlin N et al (2010) Cluster observations of emic triggered emissions in association with pc1 waves near earth's plasmapause. Geophys Res Lett 37:9

Popecki M, Arnoldy R, Engebretson M, Cahill L Jr (1993) High-latitude ground observations of pc 1/2 micropulsations. J Geophys Res 98(A12):21481-21491

Posch J, Engebretson M, Murphy M, Denton M, Lessard M, Horne RB (2010) Probing the relationship between electromagnetic ion cyclotron waves and plasmaspheric plumes near geosynchronous orbit. J Geophys Res 115:A1

Remya B, Sibeck D, Halford A, Murphy K, Reeves G, Singer H, Wygant JR, Farinas Perez G, Thaller SA (2018) Ion injection triggered emic waves in the earth's magnetosphere. J Geophys Res 123(6):4921-4938

Richardson I, Cliver E, Cane H (2000) Sources of geomagnetic activity over the solar cycle: relative importance of coronal mass ejections, high-speed streams, and slow solar wind. J Geophys Res 105(A8):18203-18213

Saikin A, Jordanova VK, Zhang J, Smith C, Spence HE, Larsen BA, Reeves GD, Torbert R, Kletzing C, Zhelavskaya I et al (2018) Comparing simulated and observed emic wave amplitudes using in situ van allen probes' measurements. Journal of Atmospheric and Solar-Terrestrial Physics

Scherliess L, Fejer BG (1997) Storm time dependence of equatorial disturbance dynamo zonal electric fields. J Geophys Res 102(A11):24037-24046

Shoji M, Omura Y (2013) Triggering process of electromagnetic ion cyclotron rising tone emissions in the inner magnetosphere. J Geophys Res 118(9):5553-5561

Shoji M, Miyoshi Y, Omura Y, Kistler L, Kasaba Y, Matsuda S, Kasahara Y, Matsuoka A, Nomura R, Ishisaka K, Kumamoto A (2018) Instantaneous frequency analysis on nonlinear emic emissions: arase observation. Geophys Res Lett 45(24):13-199

Shprits YY, Kellerman A, Aseev N, Drozdov AY, Michaelis I (2017) Multi-mev electron loss in the heart of the radiation belts. Geophys Res Lett 44(3):1204-1209

Søraas F, Laundal KM, Usanova M (2013) Coincident particle and optical observations of nightside subauroral proton precipitation. J Geophys Res 118(3):1112-1122

Summers D, Thorne RM (2003) Relativistic electron pitch-angle scattering by electromagnetic ion cyclotron waves during geomagnetic storms. J Geophys Res 108: A4

Tsurutani BT, Gonzalez WD, Guarnieri F, Kamide Y, Zhou X, Arballo JK (2004) Are high-intensity long-duration continuous ae activity (hildcaa) events substorm expansion events? J Atmos Solar-Terres Phys 66(2):167-176

Tsurutani B, Hajra R, Tanimori T, Takada A, Remya B, Mannucci A, Lakhina G, Kozyra J, Shiokawa K, Lee L et al (2016) Heliospheric plasma sheet (hps) impingement onto the magnetosphere as a cause of relativistic electron dropouts (reds) via coherent emic wave scattering with possible consequences for climate change mechanisms. J Geophys Res 121:10

Usanova M, Mann I, Bortnik J, Shao L, Angelopoulos V (2012) Themis observations of electromagnetic ion cyclotron wave occurrence: dependence on ae, symh, and solar wind dynamic pressure. J Geophys Res 117:A10

Usanova ME, Darrouzet F, Mann IR, Bortnik J (2013) Statistical analysis of emic waves in plasmaspheric plumes from cluster observations. J Geophys Res 118(8):4946-4951

Usanova M, Drozdov A, Orlova K, Mann I, Shprits Y, Robertson M, Turner D, Milling D, Kale A, Baker D et al (2014) Effect of emic waves on relativistic and ultrarelativistic electron populations: ground-based and van allen probes observations. Geophys Res Lett 41(5):1375-1381

Webb D (1995) Solar and geomagnetic disturbances during the declining phase of recent solar cycles. Adv Space Res 16(9):57-69

\section{Publisher's Note}

Springer Nature remains neutral with regard to jurisdictional claims in published maps and institutional affiliations. 